\title{
Bilayered constructs aimed at osteochondral strategies: The influence of medium supplements in the osteogenic and chondrogenic differentiation of amniotic fluid-derived stem cells
}

\author{
Márcia T. Rodrigues ${ }^{\mathrm{a}, \mathrm{b}, \mathrm{c}}$, Sang Jin Lee ${ }^{\mathrm{a}}$, Manuela E. Gomes ${ }^{\mathrm{b}, \mathrm{c}}$, Rui L. Reis ${ }^{\mathrm{b}, \mathrm{c}}$, Anthony Atala ${ }^{\mathrm{a}}$, \\ James J. Yoo ${ }^{\mathrm{a}, *}$ \\ ${ }^{a}$ Wake Forest Institute for Regenerative Medicine, Wake Forest University School of Medicine, Medical Center Boulevard, Winston-Salem, NC 27157, USA \\ b 3B's Research Group - Biomaterials, Biodegradables and Biomimetics, University of Minho, Headquarters of the European Institute of Excellence on Tissue Engineering \\ and Regenerative Medicine, AvePark, 4806-909 Taipas, Guimarães, Portugal \\ 'ICVS/3B's - PT Government Associate Laboratory, Braga/Guimarães, Portugal
}

\section{A R T I C L E I N F O}

\section{Article history:}

Received 22 November 2011

Received in revised form 4 April 2012

Accepted 9 April 2012

Available online $\mathrm{xxxx}$

\section{Keywords:}

Osteochondral defect

Amniotic fluid-derived stem cells

Osteogenic differentiation

Chondrogenic differentiation

Bilayered scaffold

\begin{abstract}
A B S T R A C T
The development of osteochondral tissue engineered interfaces would be a novel treatment for traumatic injuries and aging associated diseases that affect joints. This study reports the development of a bilayered scaffold, which consists of both bone and cartilage regions. On the other hand, amniotic fluid-derived stem cells (AFSCs) could be differentiated into either osteogenic or chondrogenic cells, respectively. In this study we have developed a bilayered scaffolding system, which includes a starch/polycaprolactone (SPCL) scaffold for osteogenesis and an agarose hydrogel for chondrogenesis. AFSC-seeded scaffolds were cultured for 1 or 2 weeks in an osteochondral-defined culture medium containing both osteogenic and chondrogenic differentiation factors. Additionally, the effect of the presence or absence of insulin-like growth factor-1 (IGF-1) in the culture medium was assessed. Cell viability and phenotypic expression were assessed within the constructs in order to determine the influence of the osteochondral differentiation medium. The results indicated that, after osteogenic differentiation, AFSCs that had been seeded onto SPCL scaffolds did not require osteochondral medium to maintain their phenotype, and they produced a protein-rich, mineralized extracellular matrix (ECM) for up to 2 weeks. However, AFSCs differentiated into chondrocyte-like cells appeared to require osteochondral medium, but not IGF-1, to synthesize ECM proteins and maintain the chondrogenic phenotype. Thus, although IGF-1 was not essential for creating osteochondral constructs with AFSCs in this study, the osteochondral supplements used appear to be important to generate cartilage in long-term tissue engineering approaches for osteochondral interfaces. In addition, constructs generated from agarose-SPCL bilayered scaffolds containing pre-differentiated AFSCs may be useful for potential applications in regeneration strategies for damaged or diseased joints.
\end{abstract}

(c) 2012 Acta Materialia Inc. Published by Elsevier Ltd. All rights reserved.

\section{Introduction}

Osteochondral interfaces are one of the most susceptible areas in the human body to traumatic injuries and aging associated diseases, such as osteoarthritis [1]. Understanding and mimicking the complexity of the osteochondral system are critical for designing a successful tissue engineering (TE) approach that can restore the functionality of a joint. However, bone and cartilage, which are the tissues that make up the osteochondral interface, have different molecular compositions and cellular organizations, which create differences in structural and mechanical properties, between

\footnotetext{
* Corresponding author. Tel.: +1 336713 7294; fax: +1 3367137290.

E-mail address: jyoo@wakehealth.edu (J.J. Yoo).
}

these tissues. Thus, current TE strategies are hampered by the difficulties inherent in designing a seamless interface between these two very different tissues.

The ideal cell source for osteochondral TE strategies has not yet been found. The cell source should be proliferative, yet it should possess the phenotypic plasticity to differentiate into the various cell types that form the osteochondral interface. Recently, amniotic fluid-derived stem cells (AFSCs) have been shown to have the capacity to differentiate along both the chondrogenic [2,3] and osteogenic [2] lineages. Also, the use of AFSCs does not raise the ethical concerns that are associated with the use of embryonic stem cells for research and therapy [4,5].

Osteochondral interfaces are exposed to a number of different in vivo stresses and strains that result from the patient's daily 
activities and movements. In addition to providing mechanical support, a scaffold for osteochondral regeneration should generate an efficient and integrated interface which enables different cell types to communicate and interact while keeping these various cells and their functions in the proper structural compartment. Agarose hydrogels have previously been used for cell culture and cartilage TE strategies [6-9], because the soft, flexible structure of this natural based gel recreates a three-dimensional environment suitable for chondrocyte maintenance [7] as well as the differentiation of mesenchymal stem cells (MSCs) into the chondrogenic lineage [7]. In addition, SPCL scaffolds, which are a blend of starch and polycaprolactone, have been previously used in TE strategies designed for bone regeneration and replacement $[10-14]$ as well as for cartilage applications $[15,16]$. SPCL scaffolds are biodegradable and biocompatible, and they are based on naturally occurring materials. These scaffolds support the adhesion and proliferation of several cell types, including endothelial [10] and stem cells [12], and assist bone neoformation in vivo, especially when used in the implantation of cell-seeded scaffolds [12].

In addition to physical support (scaffold) and a biological interface (cells), the biochemical factors involved in stimulating cell-tocell communication, differentiation, and maintenance of phenotype should also be considered when designing a tissue engineering approach. Transforming growth factor-beta (TGF- $\beta$ ) is frequently used as a standard factor in media designed to induce chondrogenic differentiation. TGF- $\beta$ is involved in chondrogenesis [17], including differentiation of progenitor cells into chondrocytes, and induces proliferation and ECM production in articular chondrocytes $[18,19]$. Conversely, in bone differentiation, dexamethasone, ascorbic acid and $\beta$-glycerophosphate are commonly used supplements for culture media designed to induce osteogenic differentiation of various stem cells. Dexamethasone, a synthetic glucocorticoid, has been shown to induce osteogenic differentiation of osteoprogenitor cells from adult bone marrow stromal-derived cells [20,21]. Ascorbic acid plays an essential role in the structure and function of skeletal tissues as it is required for human collagen synthesis. Moreover, when a potential source of phosphate ions, such as $\beta$-glycerophosphate [21], is also present, a zone of hydroxyapatite-containing mineralized ECM is formed within the collagen fibrils [22], and this mineralization of the matrix is essential for formation of bone tissue. However, although osteo- and chondrogenic media are frequently described in the literature and are used to induce the differentiation of cells into these lineages, an efficient osteochondrogenic medium, which would be able to support both osteo- and chondrogenesis and the co-culture of both bone and cartilage cells, has not been completely established, although some attempts have been described [23].

In this study, we aimed to develop a novel approach to designing functional scaffolds that would support an osteochondral interface. A novel osteochondral medium, designed to support both bone and cartilage cells, was also developed by combining some of the growth factors and nutrients associated with osteo- and chondrogenic media. Furthermore, insulin-like growth factor-1 (IGF-1) was also evaluated as a potential factor for supporting osteochondral constructs in vitro, since it is involved in several developmental and physiological functions [24] of bone and cartilage, including cartilage and bone development; chondrocyte proliferation and ECM synthesis [25,26], and osteoblast proliferation and bone formation [27].

To test the osteochondral media and our novel scaffold design, human AFSCs were either cultured on SPCL scaffolds and differentiated into osteogenic cells or encapsulated in agarose gel and differentiated into chondrogenic cells. These two cell seeded scaffolds were then brought together in order to form a combination of scaffolds that would provide a highly supportive scaffold for bone formation as well as a soft matrix for cartilage growth. The resulting single constructs were cultured for 1 or 2 weeks in our novel osteochondral media, either with or without IGF-1. At each time point, the constructs were characterized for expression of bone and cartilage specific markers to evaluate the influence of the culture media on the osteogenic or chondrogenic phenotype of the differentiated cells.

\section{Materials and methods}

\subsection{Preparation of osteochondral constructs}

SPCL scaffolds were produced by the fiber melt-spinning process [11] using an extruder equipped with a $12 \mathrm{~mm}$ diameter screw and a $0.5 \mathrm{~mm}$ monofilament die. Extrusion was performed at $150{ }^{\circ} \mathrm{C}$ and the screw speed $1 \mathrm{rpm}$. Hot fiber was driven into a cooling water bath $\left(13^{\circ} \mathrm{C}\right)$ and cold-drawn after the bath, using a caterpillar with a speed of $21 \mathrm{~m} \mathrm{~min}^{-1}$ and a winding unit with a speed of $28 \mathrm{~m} \mathrm{~min}^{-1}$. Fibers were produced in a range of 120 $500 \mu \mathrm{m}$ diameter. Fiber-mesh scaffolds were prepared by a fiber bonding process consisting of cutting and sintering the fibers obtained by the melt-spinning method [11]. Briefly, a selected amount of fibers was placed inside a mold, and heated in an oven at $120^{\circ} \mathrm{C}$. Then, immediately after removing the molds from the oven, the fibers are slightly compressed and cooled to $-15^{\circ} \mathrm{C}$. Prior to the cell culture assays, all scaffolds were cut into cylinders and sterilized using ethylene oxide.

\subsection{Cell culture and seeding}

Human AFSCs were cultured in basic amniotic fluid cell (BAFC) medium. The BAFC medium $(500 \mathrm{ml})$ contained liquid $\alpha$-MEM (HyClone Laboratories Inc., Logan, Utah, USA) with $18 \%$ Chang B (Irvine Scientific, Santa Ana, CA, USA) and 1\% Chang C (Irvine Scientific) media as well as $2 \%$ L-glutamine (HyClone Laboratories Inc.) and $15 \%$ embryonic screened fetal bovine serum (ES-FBS, HyClone Laboratories Inc.). AFSC basal medium, also called BAFC, was previously described [2] as the medium that best nourishes amniotic fluid stem cells in maintenance cultures.

Briefly, back-up human amniocentesis cultures were harvested by trypsinization, and immunoselected with c-kit. AFSCs were then subcultured at dilution of $1: 8$ and not permitted to expand beyond $60 \%$ of confluence. AFSCs were passaged 2-3 times (passage 18-20) in BAFC medium. Then AFSCs were either encapsulated in agarose hydrogels ( $2 \%$, Invitrogen, Carlsbad, CA, USA) at a concentration of $2 \times 10^{6}$ cells $\mathrm{ml}^{-1}$ for the chondrogenic layer of the bilayered scaffold or seeded onto SPCL scaffolds (4 mm diameter and $5 \mathrm{~mm}$ length) at a concentration of $8.6 \times 10^{5}$ cells/scaffold for the osteogenic layer (Fig. 1).

These cell-seeded scaffolds were cultured for 2 days in BAFC culture medium, and then the medium was exchanged for either chondrogenic (agarose hydrogel) or osteogenic (SPCL scaffold) media. The chondrogenic medium consisted of DMEM (HyClone Laboratories Inc.) supplemented with $1 \%$ antibiotic/antimicotic solution, $50 \mu \mathrm{g} \mathrm{ml}^{-1}$ L-ascorbic acid (Sigma, St. Louis, MO, USA), $1 \mathrm{mM}$ dexamethasone (Sigma), $40 \mu \mathrm{g} \mathrm{ml}^{-1}$ L-proline (Sigma), $100 \mu \mathrm{g} \mathrm{ml}^{-1}$ sodium pyruvate (Sigma), $1 \%$ ITS $(100 \times$, Sigma) and $10 \mathrm{ng} \mathrm{ml}^{-1}$ TGF- $\beta 1$ (Sigma). The osteogenic medium was composed of DMEM (HyClone Laboratories Inc.) supplemented with 10\% FBS (HyClone Laboratories Inc.) and the following osteogenic supplements: $100 \mathrm{nM}$ dexamethasone (Sigma), $50 \mu \mathrm{M}$ L-ascorbic acid and $10 \mathrm{mM}$ glycerol-2-phosphate disodium salt hydrate (Sigma). Chondrogenic differentiation of AFSCs in the agarose hydrogels was assessed after 7, 14 and 21 days in the chondrogenic media, and then the gels were characterized for cellular viability with a 


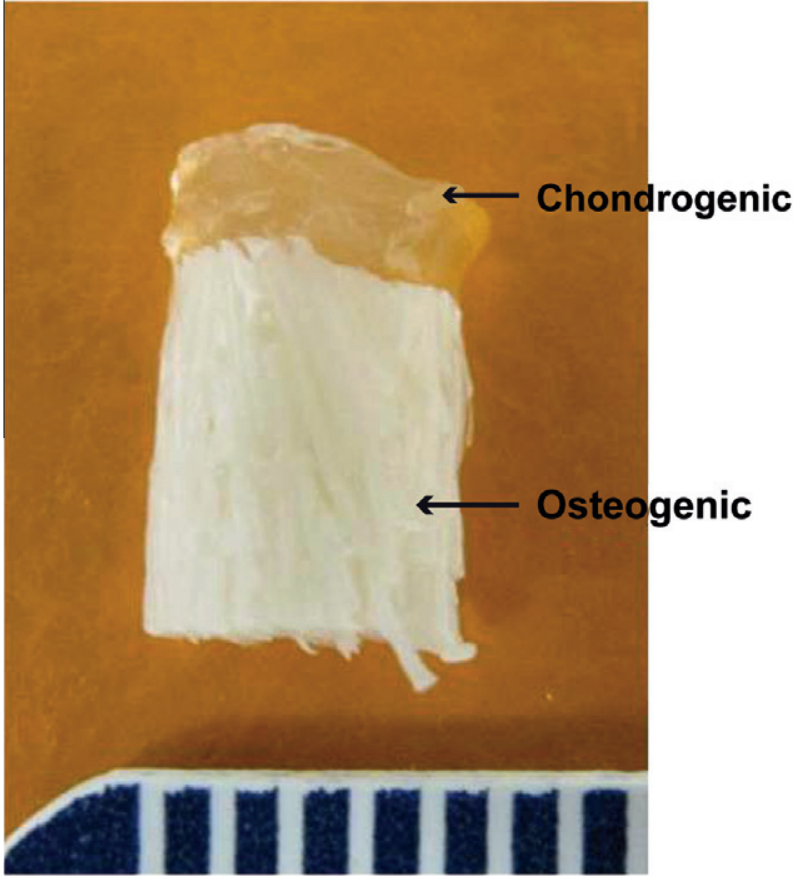

Fig. 1. Photograph of osteochondral scaffold.

Calcein AM assay, safranin-O staining, and immunofluorescence for aggrecan and collagen type II.

After both chondrogenic differentiation and osteogenic differentiation occurred in the two scaffolds, the constructs were combined by adding a drop of agarose (2\%) between the cell-encapsulated and the SPCL scaffolds to promote bonding of the two layers. Then, the bilayered constructs were cultured for 2 weeks in co-culture medium under static conditions to evaluate whether this medium could maintain differentiated AFSCs in both chondrogenic and osteogenic phenotypes at the same time. The co-culture media $(500 \mathrm{ml})$ was composed of DMEM-LG (HyClone Laboratories Inc.), $4 \mu \mathrm{g} \mathrm{ml}^{-1}$ sodium pyruvate, ITS $(1 \times), 5 \mathrm{mM}$ glycerol-2-phosphate, $50 \mu \mathrm{g} \mathrm{ml}^{-1}$ L-ascorbic acid, $10 \mathrm{mM}$ dexamethasone, and $40 \mu \mathrm{g} \mathrm{ml}^{-1} \mathrm{~L}$-proline. In some studies, the growth factor IGF-1 (100 ng ml${ }^{-1}$, Invitrogen) was added to the co-culture medium (IGF-1 (+)). After 7 and 14 days in the co-culture media, constructs were removed and characterized for the osteo- or chondrogenic markers mentioned above. BAFC medium (i.e. the basal conditions) was used as a control for this experiment.

\subsection{Cell viability assay with Calcein $A M$}

AFSCs encapsulated in the agarose gels were rinsed in PBS (HyClone Laboratories Inc.) and then were incubated in PBS containing $3 \mu \mathrm{M}$ Calcein AM (Molecular Probes, Invitrogen) for $30 \mathrm{~min}$ at $37^{\circ} \mathrm{C}$ in a $5 \% \mathrm{CO}_{2}$ environment. This incubation was followed by a quick rinse in PBS and overnight fixation in $10 \%$ buffered formalin (Surgipath Medical Ind., Inc., Richmond, IL, USA) at $4{ }^{\circ} \mathrm{C}$. AFSC viability was detected using a confocal microscope (Axiovert 100M, Zeiss, Germany) equipped with argon/He-Ne laser sources.

\subsection{Alizarin red staining and calcium quantification assay}

Alizarin red (AR) staining was directly evaluated in AFSC-SPCL constructs for the assessment of osteogenesis after 7, 14 and 21 days of culture with osteogenic supplements. An alizarin red solution ( $0.2 \%$, Sigma-Aldrich, USA) was prepared and $\mathrm{pH}$-adjusted to $\mathrm{pH}$ 4.1-4.3. Samples were cut in half and then stained via immersion in alizarin red solution for $2 \mathrm{~min}$. This was followed by a water rinse to wash away non-specific staining.

After acquiring images of the stained AFSC-SPCL constructs using an Olympus SP-570UZ digital camera, AR staining was solubilized in cetylpyridinium chloride (Sigma, USA) at pH 7.0 for 15 min under mild agitation and the calcium bonded to the AR was quantified at $562 \mathrm{~nm}$ using a plate reader (SpectraMax MS, Molecular Devices).

\subsection{Quantification of alkaline phosphatase (ALP) activity}

ALP in AFSC-SPCL constructs was measured by an enzymatic reaction followed by colorimetric analysis. At each time point (7, 14 or 21 days in osteogenic medium), cells were rinsed in PBS and placed in a microtube containing $1 \mathrm{ml}$ of ultra-pure water and kept frozen at $-80^{\circ} \mathrm{C}$ until testing. Afterwards, samples were thawed and sonicated briefly for $15 \mathrm{~min}$ in order to rupture any cells that might have maintained membrane integrity after the osmotic treatment and the freeze/thaw cycle. Then, a substrate solution consisting of $0.2 \%(\mathrm{wt} / \mathrm{v}$ ) p-nitrophenyl phosphate (Sigma, Germany) in a substrate buffer with $1 \mathrm{M}$ diethanolamine $\mathrm{HCl}$ (Panreac, Spain), at $\mathrm{pH} 9.8$ was added to each sample, at a proportion of $60 \mu \mathrm{l}$ of solution to $20 \mu \mathrm{l}$ of sample.

Samples were incubated in the dark for $45 \mathrm{~min}$ at $37^{\circ} \mathrm{C}$. This reaction was followed by the addition of a stop solution ( $2 \mathrm{M} \mathrm{NaOH}$ (Panreac, Spain) plus 0.2 mM EDTA (Sigma, Germany)) to end the color development reaction. Standards were prepared with pnitrophenol (10 $\mu \mathrm{mol} \mathrm{ml}^{-1}$ ) (Sigma, Germany) in order to achieve final concentrations ranging between 0 and $0.3 \mu \mathrm{mol} \mathrm{ml}^{-1}$. Samples and standards were analyzed in triplicate.

The absorbance was read using a microplate ELISA reader (Synergie HT, BioTek) at $405 \mathrm{~nm}$ and concentration values were determined by interpolation using a standard curve established by the standards.

\subsection{Scanning electronic microscopy (SEM)}

Bilayered constructs were rinsed in PBS, fixed in $10 \%$ buffered formalin overnight, and dehydrated in a series of ethanol concentrations and critical point dried (EMS850X, Electron Microscopy Sciences, Hatfield, PA, USA). The scaffolds were then sputtered with gold (Hummer 6.2 sputtering system, Anatech Ltd, Union City, CA, USA). This procedure destroys the structure and morphology of AFSC-agarose hydrogels and therefore, SEM observation was only used for the AFSC-SPCL constructs of the OC system (Hitachi S$2600 N$, Hitachi Science Systems, Ltd, Japan). Additionally, in order to detect specific ions that eventually became present at the surface of cell seeded SPCL constructs on the ECM, such as calcium $\left(\mathrm{Ca}^{2+}\right)$ and phosphorus (P), an energy dispersive spectroscopy (EDS) analysis was performed with EDAX (Pegasus X4M, EDS/EBSD, EDAX BV, JC Tilburg, Netherlands). Each EDS analysis involved four replicates $(n=4)$ per study condition.

\subsection{Histological characterization}

For histological evaluation, the samples were rinsed in PBS, fixed in $10 \%$ buffered formalin overnight and processed using a tissue processor (Microm STP120, MICROM International GmbH, Walldorf, Germany). Next, each sample was embedded in paraffin blocks (Microm EC 350-2, ThermoScientific, Spain), and $10 \mu \mathrm{m}$ thick sections were cut and stained with safranin-O (Fluka, Switzerland). Safranin-O is a cationic dye frequently used for the detection of cartilage. Following deparaffinization of AFSC-agarose samples, slides were stained with Weigert's iron hematoxylin working solution (Sigma-Aldrich, Germany) for $7 \mathrm{~min}$. Samples were rinsed in tap water for $10 \mathrm{~min}$, and subsequently rinsed 
quickly in $1 \%$ acetic acid (Fluka) solution for $\sim 10-15 \mathrm{~s}$ and stained in $0.1 \%$ safranin-O solution for $5 \mathrm{~min}$.

Immunofluorescence analysis for collagen type II and aggrecan was also carried out. Sections were cut from the paraffin blocks, deparaffinized and rehydrated with a graded series of ethanol concentrations. Prior to incubation with primary antibodies for either mouse anti-collagen II (MAB1330, Millipore, Spain) or mouse antihuman aggrecan (MCA1452, Serotec, Germany; dilution 1:25), slides were blocked with horse serum (VectorLabs) for $45 \mathrm{~min}$. This was followed by an incubation with 4,6-diamidino-2-phenyindole, dilactate (DAPI at $5 \mu \mathrm{g} / \mu \mathrm{l}$; D9564, Sigma, Germany) for $15 \mathrm{~min}$. Next, samples were formalin-fixed for an additional $30 \mathrm{~min}$ to prevent fluorescence dilution 1:75. Samples were incubated with primary antibodies prepared in antibody diluent with background reducing components from Dako (Dako, Denmark) overnight at $4{ }^{\circ} \mathrm{C}$. After rinsing in PBS, the samples were incubated with rabbit anti-mouse Alexa Fluor 488-conjugated secondary antibody (A11059, Invitrogen, Spain; dilution 1:200) for $1 \mathrm{~h}$ at room temperature. Samples were washed again in PBS from leaching out of the stained areas.

Samples were observed under a microscope (Zeiss Imager Z1m, Germany) and images were acquired using a digital camera (AxioCam MRm5). Multiple sections were viewed per time point and per antibody group.

Negative controls were assessed for immunofluorescence detection. Negative controls followed the same protocol as the test samples without the incubation with the primary antibody.

Immunofluorescence on the osteogenic layer (AFSC-SPCL constructs) of the bilayered construct was performed directly on the sample after the system was disassembled to assess the presence of the bone factor RunX-2. Initially, samples were rinsed and incubated with a protein blocking solution (Dako, Denmark), followed by an incubation with antibody to RunX-2 (Rabbit polyclonal to RUNX2, ab23981, Abcam, Cambridge, MA, USA) (1:100 dilution) prepared in antibody diluent with background reducing components from Dako. Antibody binding was assessed using anti-rabbit AlexaFluor 488 (Molecular Probes, 1:200 dilution) as a secondary antibody.

\subsection{Statistical analysis}

All quantitative results are expressed as the mean \pm standard deviation. One-way ANOVA followed by Bonferroni's multiple comparison test was used in calcium and ALP quantification assays while EDS analysis for the atomic percentage of calcium and phosphorus was assessed by two-way ANOVA followed by Bonferroni's multiple comparison test. Both one-way and two-way ANOVA were assessed to determine whether differences between sample groups were significant. Differences were considered significant when the $p$ value was $<0.05$.

\section{Results}

\subsection{AFSC-agarose scaffold}

The AFSC-agarose encapsulation systems were stable during the experimental period. AFSCs remained viable during the 21day culture period regardless of the type of medium used (basal or chondrogenic), as shown in Fig. 2. Nevertheless, the intensity of Calcein AM fluorescence in the AFSCs in basal culture media appeared to be higher than that seen in the chondrogenic environment. Furthermore, the differentiation of AFSCs into chondrocyte-like cells was assessed by examining protein expression of collagen type II and aggrecan by immunofluorescent analysis.
Collagen type II expression was detected as early as 7 days into culture of AFSCs encapsulated in agarose gel in both basal and chondrogenic cultures. Collagen II expression is lost in basal medium at week 2 and, by week 3, reappears and increases, while AFSC-agarose gels cultured in chondrogenic medium show a more constant expression of collagen II with the time in culture (Fig. 3). As observed in Fig. 4, overall, aggrecan expression is less than that of collagen II. In basal medium, AFSCs encapsulated in agarose hydrogels expressed a low level of aggrecan for the 3 weeks of this experiment (Fig. 4).

Although cells are present as observed by DAPI staining (inset images), in chondrogenic medium the intensity seems to be lower than in basal conditions.

Briefly, our results show that in the agarose gels, strong collagen type II expression and lower expression of aggrecan are present with some fluctuations from week 2 to week 3 .

\subsection{AFSC-SPCL scaffold}

The osteogenic potential of AFSCs on SPCL scaffolds was evaluated by ALP activity, alizarin red staining and observation of the synthesis of a calcified mineralized matrix.

As observed in Fig. 5, ALP levels were very low at day 0 (AFSCSPCL constructs without osteogenic supplements). After 1 week in osteogenic medium, ALP activity increased significantly $(p<0.05)$, although enzymatic values stabilized from day 7 to day 14 $(p>0.05)$. Nevertheless, at day 21, the amount of ALP measured was considerably higher than any other end point in the experiment $(p<0.05)$.

Only the image of AFSC-SPCL constructs at day 21 in osteogenic medium developed the characteristic alizarin red color associated with the alizarin-calcium complex that forms in the presence of calcium (Fig. 6).

Moreover, the observed stain is homogeneously dispersed throughout the fibers of the scaffold. After stain dissolution, the calcium content graph clearly indicates the increase in calcium levels in AFSC-SPCL constructs after 21 days in osteogenic culture $(p<0.05)$, when compared to the other end points in this study.

\subsection{Agarose-SPCL bilayered system}

The AFSCs seeded onto the SPCL scaffold proliferated well and were able to differentiate to osteogenic cell type in the different culture media. In the SEM micrographs of these constructs (Fig. 7), the cells were distributed throughout the scaffold, and some mineralization nodules could be seen at the surface of the SPCL fibers (indicated by white arrows in Fig. 7), suggesting the formation of a calcified ECM. Larger mineralized aggregates were found when IGF-1 was added to the OC culture medium after 1 week of culture in this medium. Although these nodules did not increase in size with time, the mineralization observed in the SPCL constructs was stable and was still evident after 2 weeks of culture in the $\mathrm{OC}$ medium.

EDS analysis was also performed at the surface of the constructs after assembly of the OC constructs. Two EDS analyses were considered; the first was broader and included several areas of the construct that contained cells with and without mineralization nodules (Table 1 ), and the second analysis included only areas in which mineralization was present (Table 2).

The detection of calcium (Ca) and phosphorus ions (P) via EDS has been associated with the production of mineralized matrices by cells. In this study, P, Ca and the ratio $\mathrm{Ca} / \mathrm{P}$ were assessed in the AFSC-SPCL layer after 7 and 14 days in osteochondral cultures (Figs. 8 and 9).

Calcium and phosphorus tend to decrease with culture time, with an exception made for constructs cultured in IGF $(+)$ medium, 

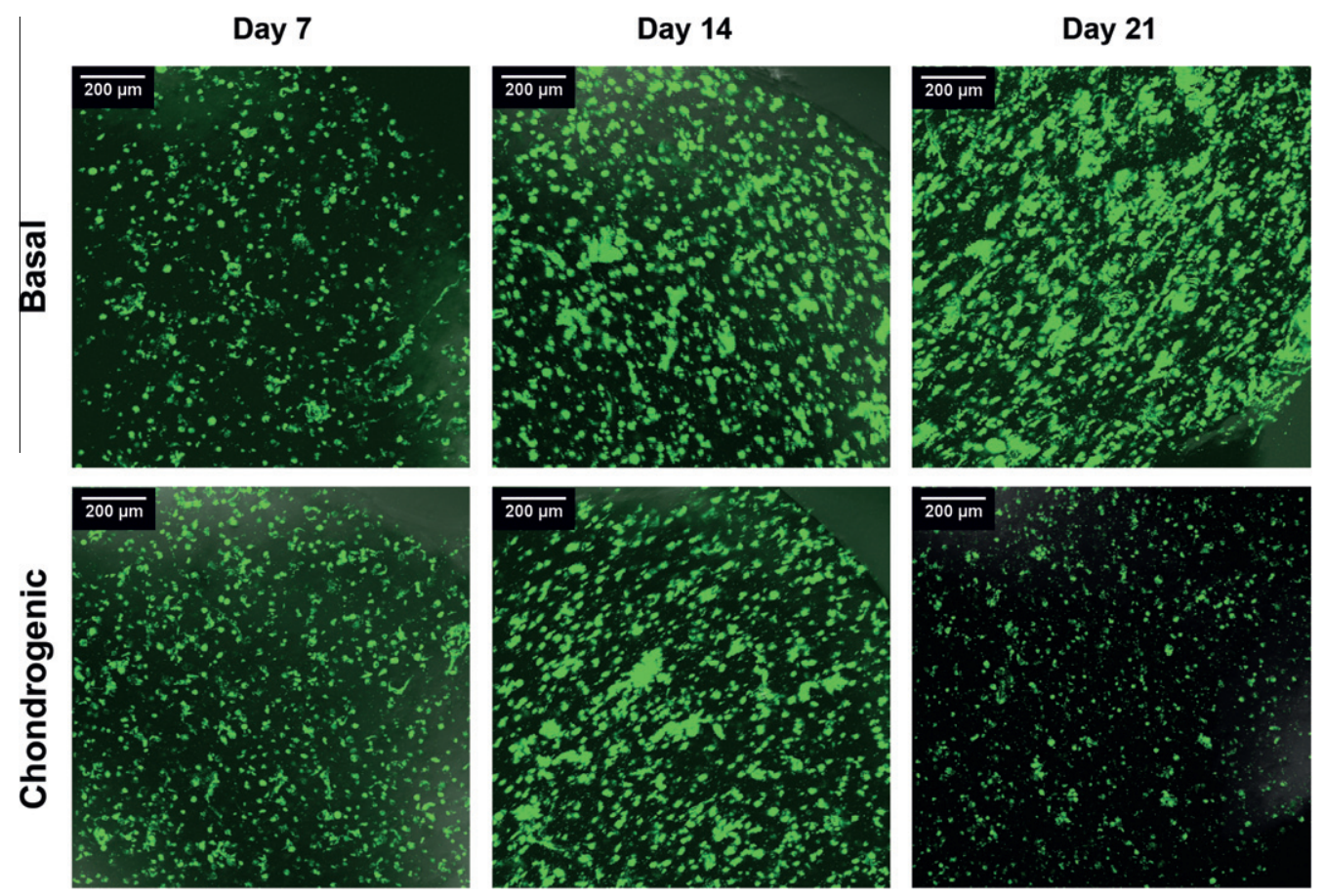

Fig. 2. Cell viability (Calcein AM) of AFSCs encapsulated in agarose hydrogels, after 7, 14 or 21 days in chondrogenic and basal media (control). Scale bar represents $200 \mu$ m.

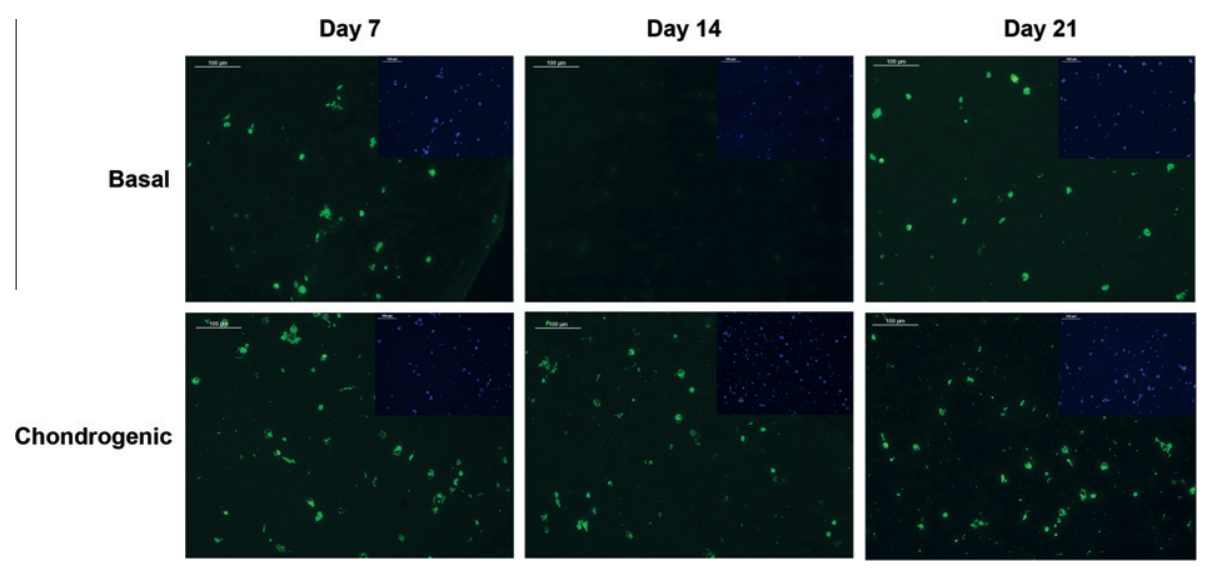

Fig. 3. Immunofluorescence analysis of collagen type II expression in AFSCs encapsulated in agarose gels after 7, 14 or 21 days in chondrogenic and basal media (control). Scale bar represents $100 \mu \mathrm{m}$, magnification, 200×.

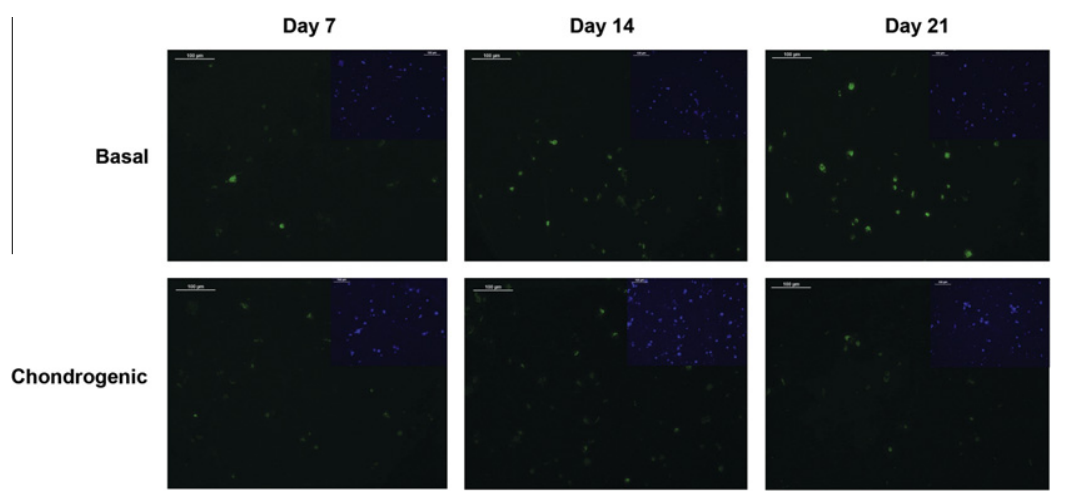

Fig. 4. Immunofluorescence analysis of aggrecan expression in AFSCs encapsulated in agarose hydrogels after 7, 14 or 21 days in chondrogenic or basal media (control). Scale bar represents $100 \mu \mathrm{m}$, magnification, 200×.

Please cite this article in press as: Rodrigues MT et al. Bilayered constructs aimed at osteochondral strategies: The influence of medium supplements in the osteogenic and chondrogenic differentiation of amniotic fluid-derived stem cells. Acta Biomater (2012), http://dx.doi.org/10.1016/j.actbio.2012.04.013 


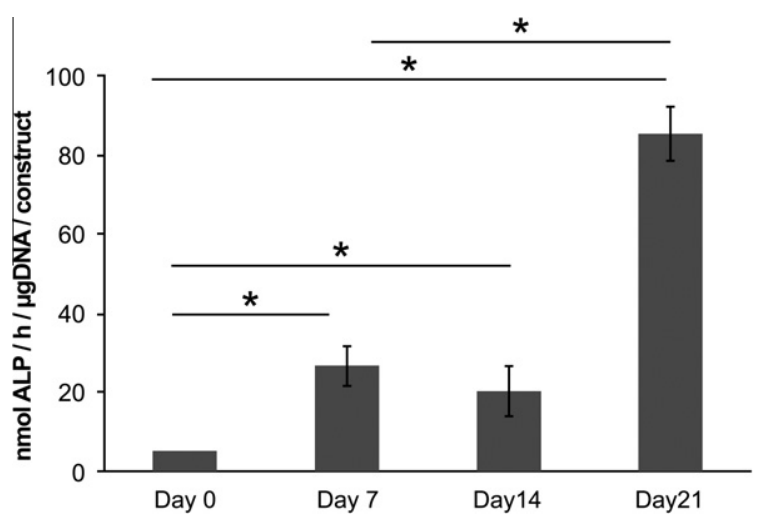

Fig. 5. Alkaline phosphatase activity (nmol h ${ }^{-1}$ per $\mu$ g DNA) of AFSCs seeded onto SPCL scaffolds after 7, 14 or 21 days in osteogenic medium. Day 0 represents a control of the experiment where AFSCs were seeded and maintained in AFSC basic medium for two days, without the addition of osteogenic medium. Data are normalized per amount of DNA of each construct and values are represented as mean \pm SD. The symbol * denotes end points with statistically significant differences $(p<0.05)$ via the one-way ANOVA method.

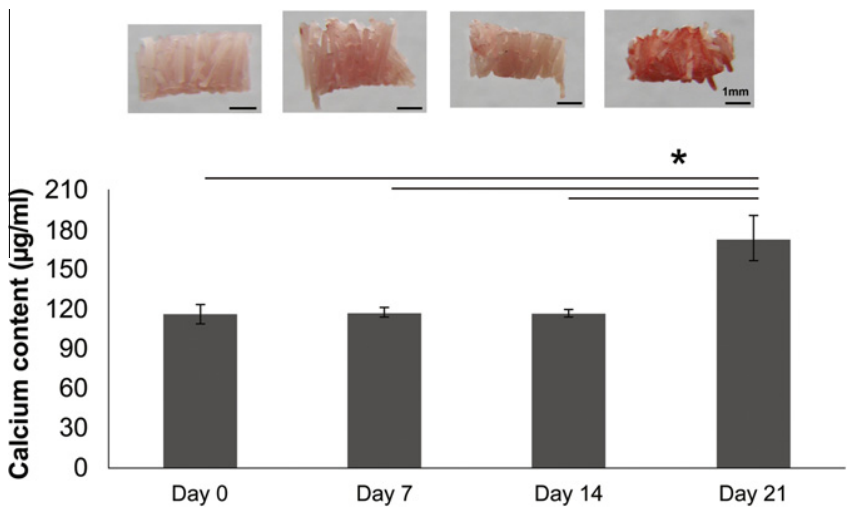

Fig. 6. Alizarin red staining and calcium content ( $\mu \mathrm{g} \mathrm{ml}^{-1}$ per well) of AFSC-SPCL constructs cultured in osteogenic medium for $0,7,14$ or 21 days. Day 0 represents a control of the experiment where AFSCs were seeded and maintained in AFSC basic medium for two days, without the addition of osteogenic medium. Values are represented as mean $\pm S D$. The symbol * denotes end points with statistically significant differences $(p<0.05)$ via the one-way ANOVA method.
Table 1

Results obtained from EDS analysis of the atomic percentage (at.\%) of several ions present in AFSC-SPCL layer after 7 or 14 days in the OC culture media (broad analysis).

\begin{tabular}{llll}
\hline At.\% & $\mathrm{P}$ & $\mathrm{Ca}$ & $\mathrm{Ca} / \mathrm{P}$ \\
\hline 7d IGF-1 $(+)$ & $0.385 \pm 0.199(*)$ & $0.380 \pm 0.072$ & $0.840 \pm 0.044$ \\
7d IGF-1 $(-)$ & $0.553 \pm 0.041(*)$ & $0.730 \pm 0.286(*)$ & $1.350 \pm 0.666$ \\
7d basal & $1.240 \pm 0.451(*)$ & $1.328 \pm 0.681(*)$ & $1.039 \pm 0.153$ \\
14d IGF-1 $(+)$ & $0.995 \pm 0.660(*)$ & $0.883 \pm 0.977(*)$ & $0.786 \pm 0.299$ \\
14d IGF-1 (-) & $0.485 \pm 0.142(*)$ & $0.518 \pm 0.225(*)$ & $1.050 \pm 0.127$ \\
14d basal & $0.708 \pm 0.214(*)$ & $0.965 \pm 0.431(*)$ & $1.313 \pm 0.312$ \\
\hline
\end{tabular}

Represented ions are: P (phosphorus), Ca (calcium). Ca/P represents the ratio of calcium/phosphorus. The symbol ${ }^{*}$ denotes statistical significance $(p<0.05)$ between the atomic percentage of ions found in broad analysis and mineral aggregate analysis.

Table 2

Results obtained from EDS analysis of the atomic percentage (at.\%) of several ions present in AFSC-SPCL layer after 7 or 14 days in the OC culture media. EDS analysis was performed on areas of the constructs containing mineralized aggregates.

\begin{tabular}{llll}
\hline At.\% & $\mathrm{P}$ & $\mathrm{Ca}$ & $\mathrm{Ca} / \mathrm{P}$ \\
\hline 7d IGF-1 $(+)$ & $2.550 \pm 1.293(*)$ & $2.503 \pm 0.261$ & $0.942 \pm 0.062$ \\
7d IGF-1 $(-)$ & $3.128 \pm 0.527(*)$ & $3.363 \pm 0.767(*)$ & $1.073 \pm 0.026$ \\
7d basal & $5.345 \pm 0.727(*)$ & $5.588 \pm 0.822(*)$ & $1.043 \pm 0.069(*)$ \\
14d IGF-1 (+) & $2.865 \pm 1.557(*)$ & $3.135 \pm 2.555(*)$ & $1.042 \pm 0.163$ \\
14d IGF-1 (-) & $3.288 \pm 0.675(*)$ & $3.593 \pm 0.705(*)$ & $1.098 \pm 0.076$ \\
14d basal & $3.670 \pm 0.963(*)$ & $4.553 \pm 1.301(*)$ & $1.240 \pm 0.042(*)$ \\
\hline
\end{tabular}

Represented ions are: P (phosphorus), Ca (calcium). Ca/P represents the ratio of calcium/phosphorus. The symbol ${ }^{*}$ denotes statistical significance $(p<0.05)$ between the atomic percentage of ions found in broad analysis and mineral aggregate analysis; with the exception of $\mathrm{Ca} / \mathrm{P}$ values in which the symbol * denotes statistical significance $(p<0.05)$ between 7 and 14 days in the basal culture media.

in which these ion levels tend to increase after 14 days in culture. Some variations were observed with culture time and media in the broad analysis but they were not statistically relevant $(p>0.05)$ (Fig. 8, Table 1). The atomic concentrations of both of these minerals were higher $(p<0.05)$ on the mineral nodules formed than the ones observed in the broader analysis shown in Table 1 and Fig. 8 , with the exception made for calcium detected in AFSC-SPCL scaffolds after 7 days in culture medium with IGF (+). Interestingly, in the mineral aggregates analysis, the higher atomic percentages
IGF-1 (+)
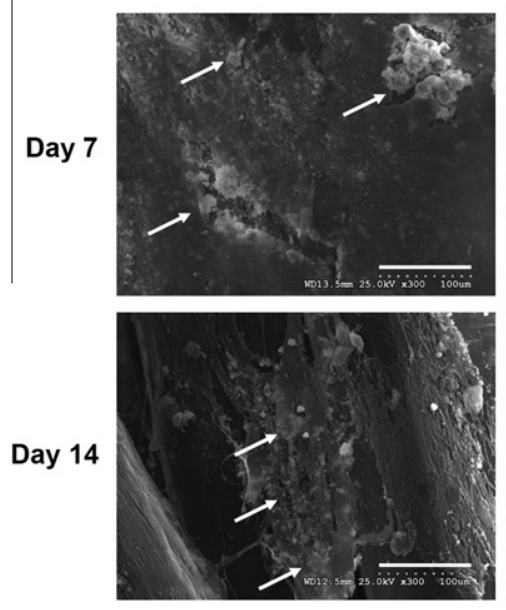

IGF-1 (-)
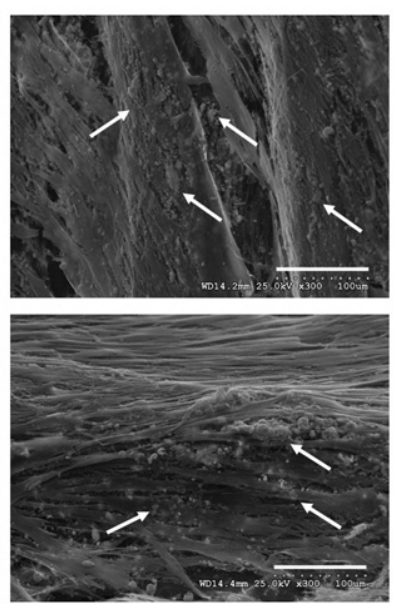

Basal
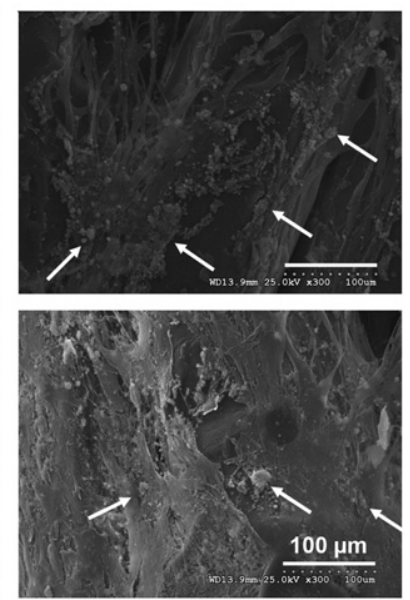

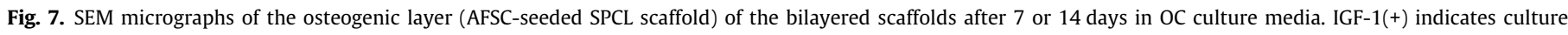

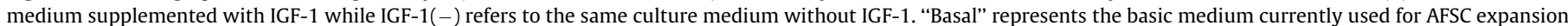

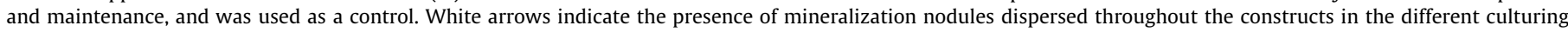
conditions. Scale bar represents $100 \mu \mathrm{m}$, magnification $300 \times$. 


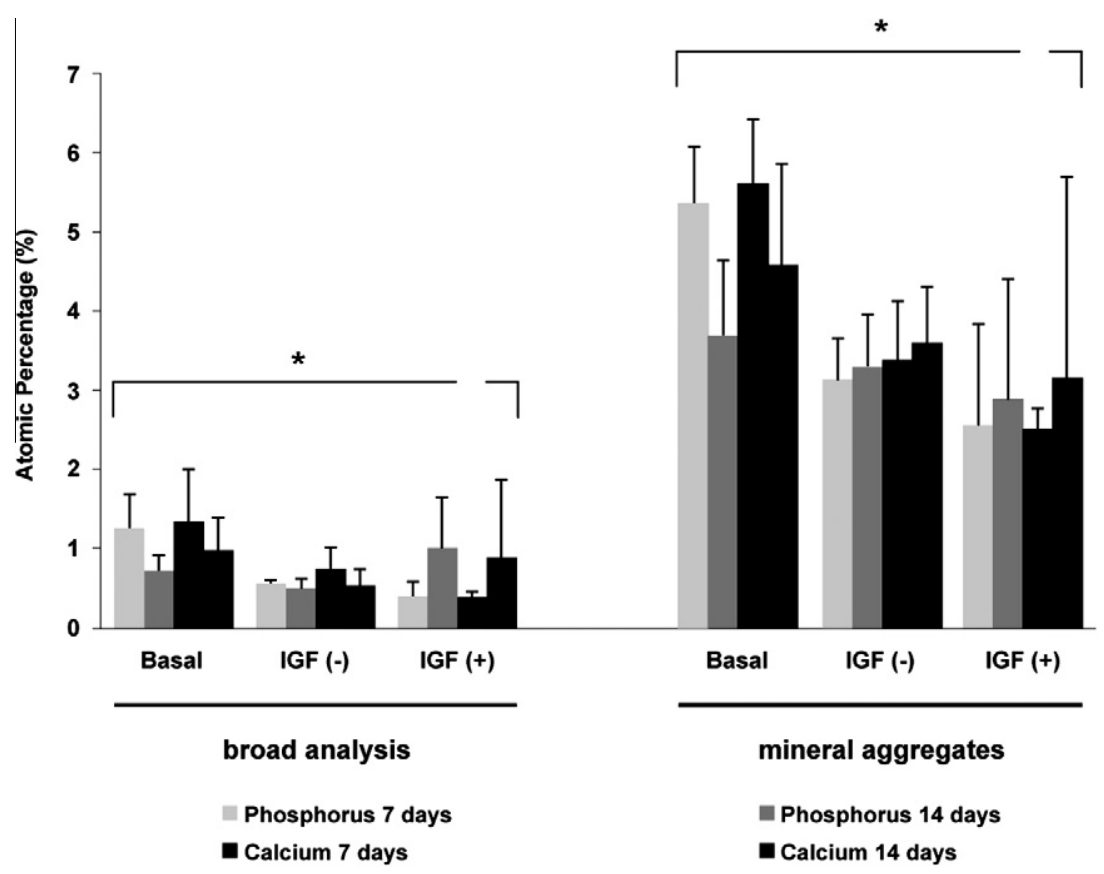

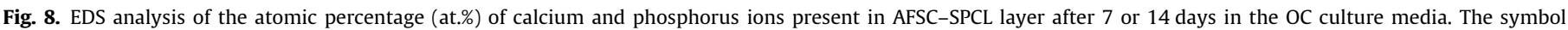

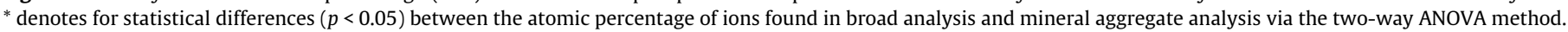

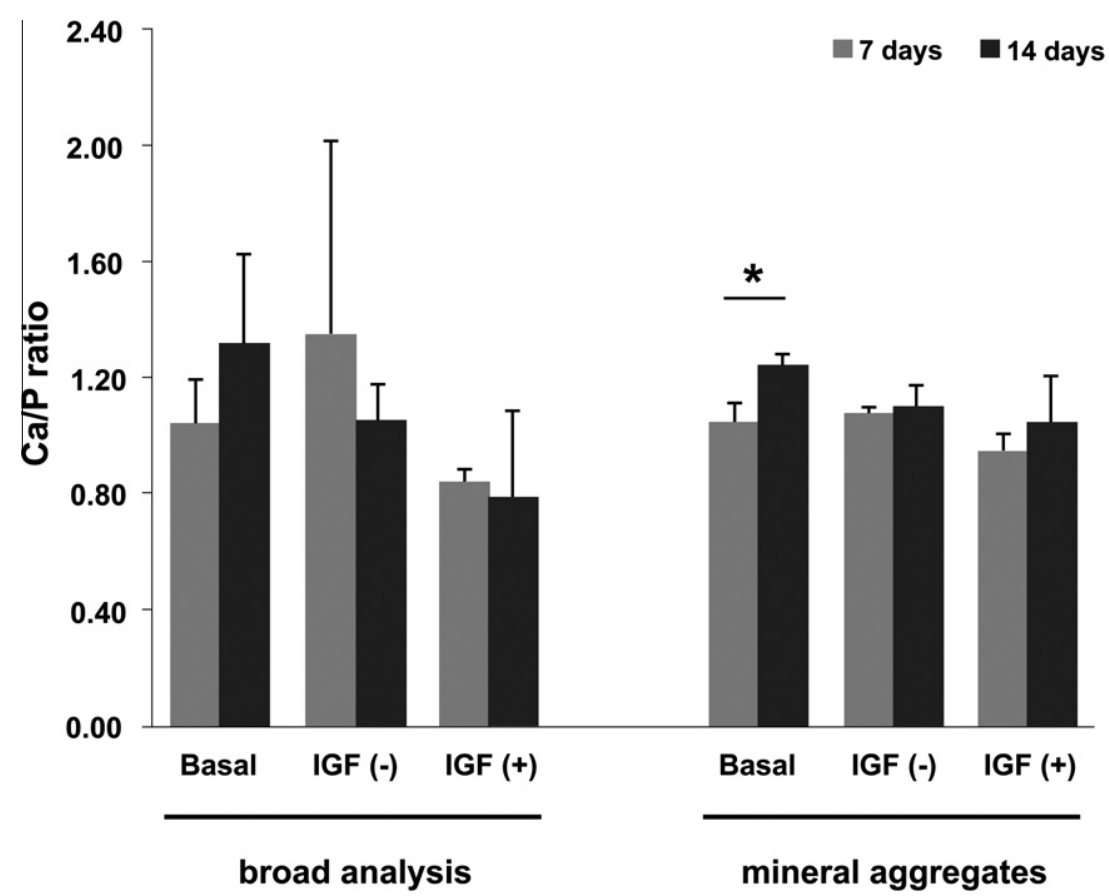

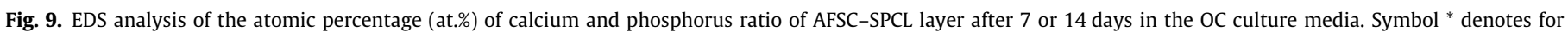
statistical differences $(p<0.05)$ via the two-way ANOVA method.

of calcium and phosphorus were observed in the basal medium condition $(p>0.05)$ (Fig. 8, Table 2).

Afterwards, the $\mathrm{Ca} / \mathrm{P}$ ratio was analyzed (Fig. 9) so as to compare its proximity to the ratio observed in natural bone: 1.67 [28].

In the broad analysis, the $\mathrm{Ca} / \mathrm{P}$ ratio was close to 1 at both 7 and 14 days in constructs maintained in OC medium without IGF- 1 and basal medium, while in AFSC-SPCL scaffolds cultured in the presence of IGF-1, the $\mathrm{Ca} / \mathrm{P}$ ratio was found to be close to 0.8 . Despite these variations, no significant differences were found with culture time or culture media. When the analysis was performed specifically on mineralized nodules, $\mathrm{Ca} / \mathrm{P}$ ratios showed closer values among different culture conditions (Table 2, Fig. 9).

When the $\mathrm{Ca} / \mathrm{P}$ ratio was calculated, all culture conditions but one resulted in a ratio of 1 (Table 2). Furthermore, the constructs cultured for 14 days in basal medium after the OC assembly were found to have $\mathrm{Ca} / \mathrm{P}$ ratio closer to that found in healthy bone (1.67) [28], namely $1.313 \pm 0.312$ and $1.240 \pm 0.042$, after an EDS broad analysis and on mineralized aggregates, respectively.

In our previous study [29], AFSCs were shown to express RunX2 during osteogenic differentiation over a period of up to 3 weeks 
in osteogenic medium. In the present study, we analyzed possible differences in RunX-2 expression 2 weeks after the novel OC media was added to the constructs (Fig. 10). RunX-2 expression was higher when the cells were cultured in OC media than when they were cultured in basal medium.

Cell viability in the AFSC-containing agarose gels was qualitatively analyzed using a Calcein AM assay after the chondrogenic differentiation process. Fig. 11 indicates that most cells remained viable during the culture period, and viability was independent of the medium used for culture. Furthermore, cellular viability was high both at the surface/border and in the center areas of the gels, indicating that the agarose gels were permeable enough to allow the exchange of nutrients and gases between the culture media and the encapsulated cells.

Collagen type II expression within the gels was assessed by immunofluorescence. Fig. 12 indicates that collagen type II was present in the constructs for up to 14 days after the addition of OC media. However, expression of this chondrogenic marker was similar in the assembled bilayered construct than in AFSC-containing agarose gels alone, and this was true whether the constructs were cultured in basal or chondrogenic media.

The exception is AFSC-agarose constructs cultured under basal medium for 14 days, which increased in OC media in this period of time. According to Fig. 12, the collagen II expression seems to be increased in the culture medium without IGF supplementation. In the presence of IGF, collagen II tends to be more abundant at both 7 and 14 days of osteochondral culture.

The expression of aggrecan in the bilayered constructs was very mild at 7 days in all osteochondral media. Nevertheless, by day 14 some of the expression is already restored, yet with lower levels than collagen II. This suggests that the presence of OC media influences type II collagen expression in the bilayered system (Fig. 13).

Safranin-O staining is used to identify areas of cartilage production in tissue sections. When we performed this stain on sections taken from the bilayered OC constructs, the chondrogenic layer (AFSC-agarose gel) stained positively in sections from all samples cultured in OC medium without IGF-1 after 14 days of culture, as shown in Fig. 14. In basal medium as well as in medium containing IGF-1, the safranin-O staining intensity is very low.

\section{Discussion}

\subsection{AFSC-agarose scaffold}

The AFSC-agarose encapsulation systems remained viable during the 21-day culture period as indicated by the intensity of Calcein AM fluorescence in Fig. 1.

In native cartilage, only a limited number of chondrocytes are able to form functional cartilage tissue. In addition, in native cartilage, chondrocytes are limited in number but are able to maintain a healthy extracellular matrix, and this suggests that relatively few cells are able to provide functional cartilage tissue. In our study, we based our cell numbers on this naturally occurring phenomenon, and thus, we reduced the number of encapsulated cells to a minimum number at which cells were still able to maintain the capacity to differentiate and produce extracellular matrix. Furthermore, the low cell density proposed is supported by other cartilage studies [30-32]. Some studies also state that the low cell density in agarose gels allows low amounts of regulation factors to be effective [30], which could also provide some evidence that successful chondrogenic differentiation is possible with low cell numbers in vitro. Interestingly, the viability of AFSCs in basal culture medium appeared to be higher than that seen in the chondrogenic environment. As basal medium is specifically formulated for cell maintenance and expansion, AFSCs may have been able to proliferate at a higher rate when cultured in basal medium in AFSCagarose constructs. Conversely, chondrogenic medium directs AFSCs towards the chondrogenic differentiation process and thus stimulates the cells to stop proliferating and begin expressing ECM proteins. This result is expected, because during mammalian development, proliferation usually inhibits differentiation, while differentiation is accompanied by cell cycle withdrawal [33]. The inverted relationship between proliferation and differentiation has been previously reported in osteoprogenitor cells [34]. Besides water, the cartilage matrix consists of macromolecules in which collagen type II ( $\sim 80 \%$ of the total tissue collagen) and proteoglycans (aggrecan) are the main structural representatives [35], and these molecules are responsible for tissue formation. When MSCs differentiate into chondrocytes, collagen type II expression begins in a final stage of undifferentiated MSCs, and then increases significantly in the chondroprogenitor stage and again as chondroprogenitor cells differentiate into chondrocytes [36]. This may explain why collagen type II is expressed at all time points in this study. Undifferentiated AFSCs tend to express a number of markers that are similar to MSCs [2,37], indicating that they may be similar or related cells. Thus, it is not surprising that the chondrogenic differentiation of AFSCs may follow a similar time course as MSCs in terms of collagen type II expression. However, it has been shown that the aggrecan is available in smaller amounts in cartilage ECM than collagen type II [35], and we have also observed this in our study (Fig. 4). The pattern of aggrecan expression observed in this study is supported by data showing that during skeletogenesis, chondroprogenitor determination and chondrocyte differentiation are accompanied by dynamic ECM remodeling [36]. Aggrecan expression in the ECM increases as chondrocytes differentiate and become hypertrophic [36]. Interestingly, the higher levels of aggrecan expression were observed in AFSC-agarose scaffolds cultured in basal medium in comparison to chondrogenic medium

\section{IGF-1 (+)}

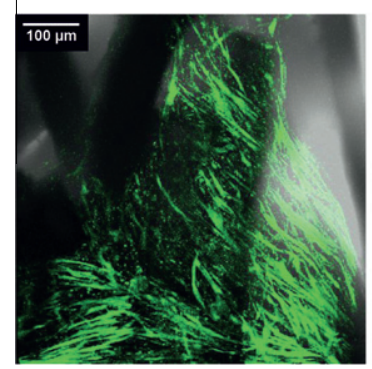

IGF-1 (-)

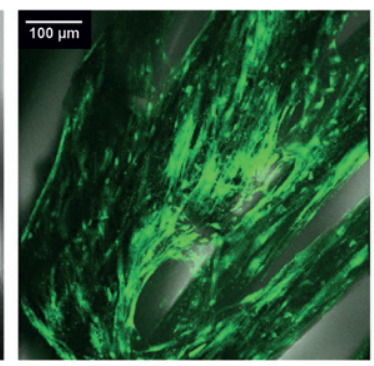

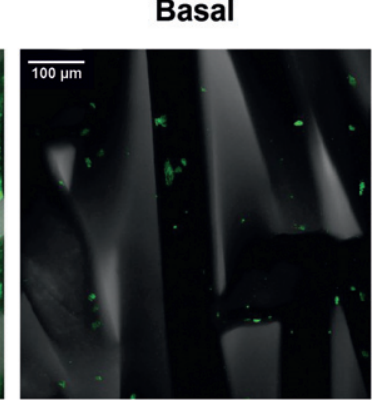

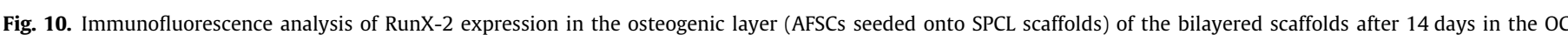

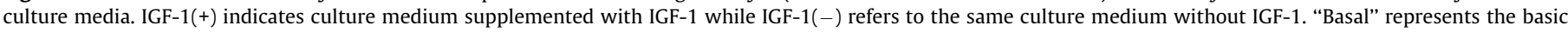
medium currently used for AFSC expansion and maintenance, and was used as a control. Scale bar represents $100 \mu \mathrm{m}$. 
IGF-1 (+)
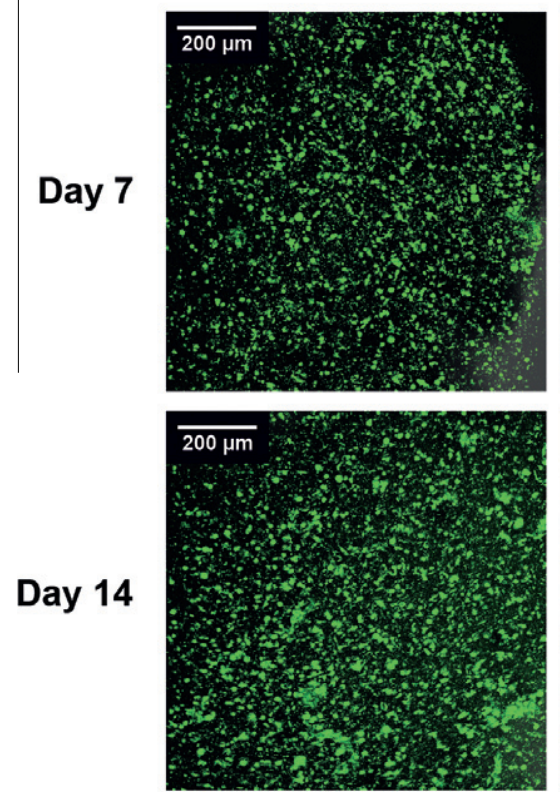

IGF-1 (-)
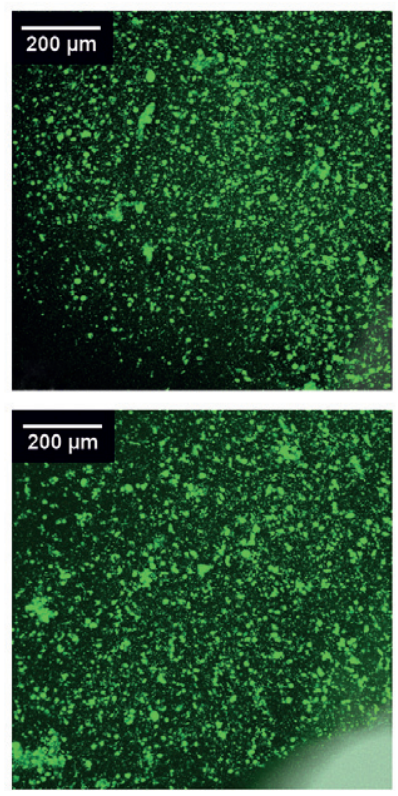

Basal
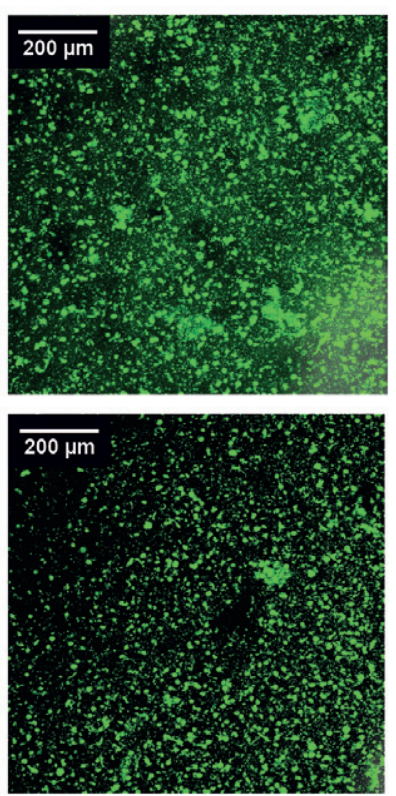

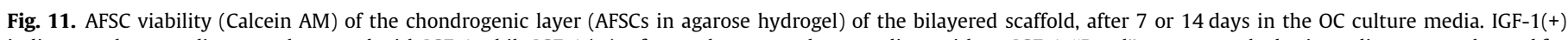

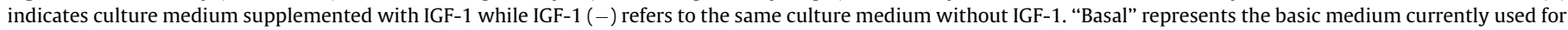
AFSC expansion and maintenance, and was used as a control. Scale bar represents $200 \mu \mathrm{m}$.
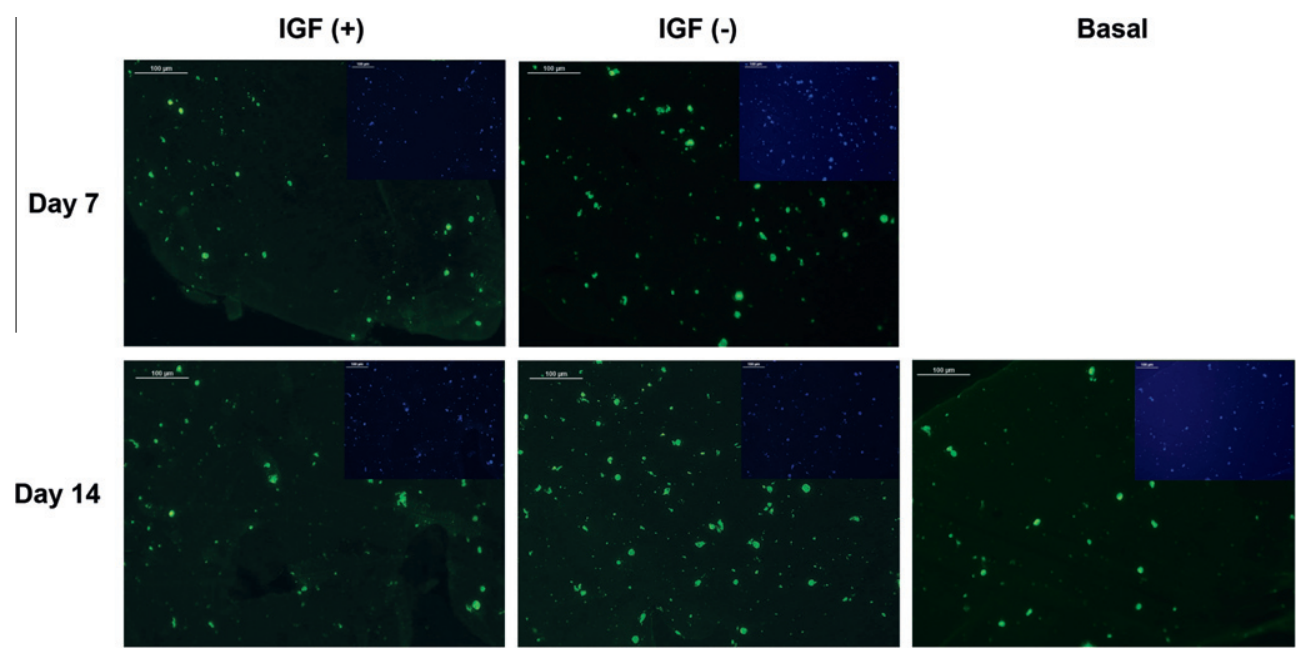

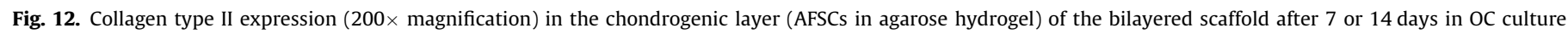

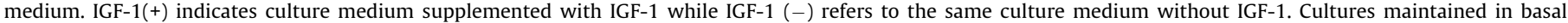

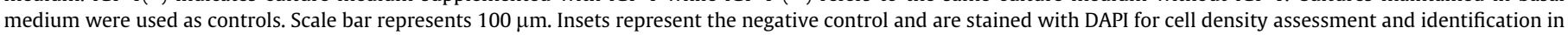
the sections.

culture. Chondroprogenitor cells and chondrocytes express high levels of collagen type II and increasing levels of aggrecan in the ECM. Nevertheless, as chondrocytes move into a hypertrophic state, low expression levels of collagen type II and high aggrecan levels are observed [36]. Thus, by week 3, AFSCs may still be in an early stage of chondrocyte differentiation.

\subsection{AFSC-SPCL scaffold}

Alkaline phosphatases (ALPs) are a group of enzymes found in several organs. In living organisms bone related ALP is present in vesicles secreted by osteoblasts to induce bone mineralization, while in vitro ALP has been associated with ECM development and maturation [34]. Consequently, ALP activity has been consid- ered an osteogenic marker and is often evaluated in studies investigating stem cell differentiation to bone.

Our results show that some expression of ALP is already detected on day 0 , indicating that these levels are likely to be basal amounts of ALP, naturally expressed in undifferentiated AFSCs seeded on SPCL scaffolds. The significant increment from day 0 to day $7(p<0.05)$ is likely to be associated to the presence of osteogenic factors in the culture medium as well as the induction of AFSCs towards an osteogenic phenotype, which was kept stable from week 1 to week 2 in osteogenic medium $(p>0.05)$. Nevertheless, ALP activity significantly increases in AFSC-SPCL constructs after 21 days in osteogenic culture medium $(p<0.05)$. This increment is associated to a stage of osteogenic differentiation in which the development and maturation of an ECM has a critical role on 

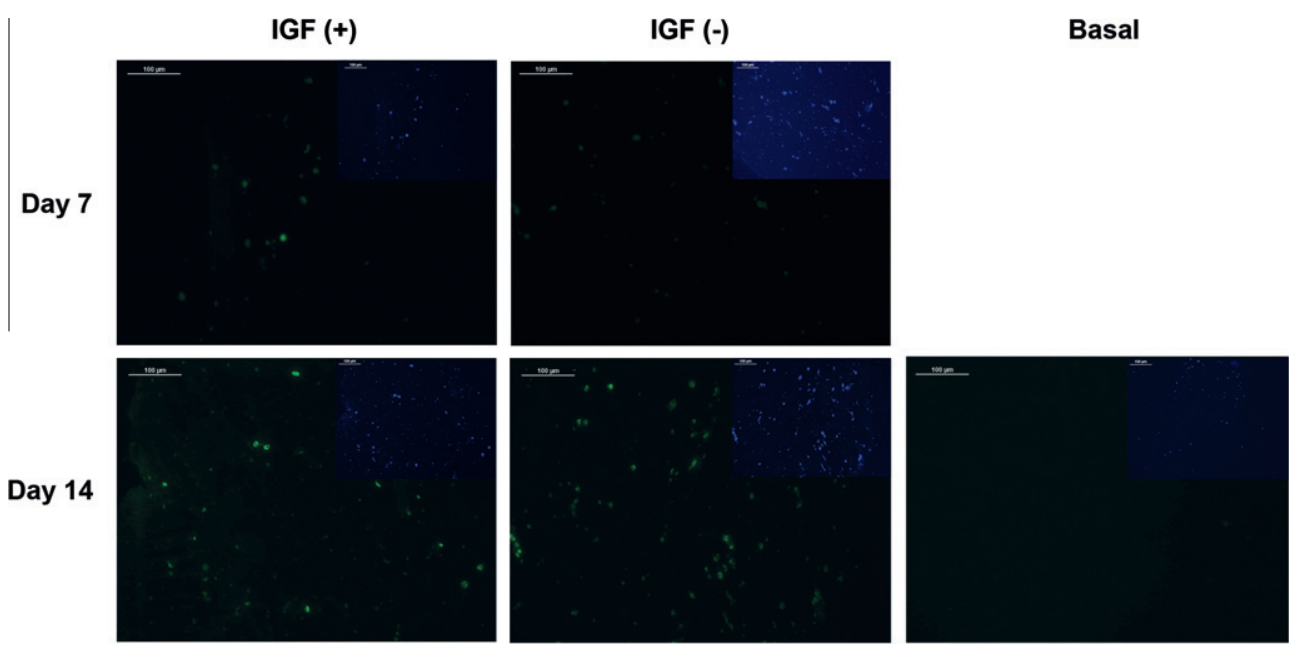

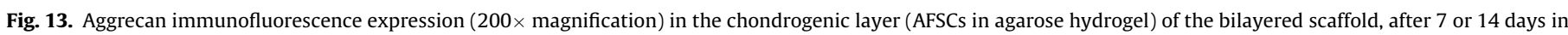

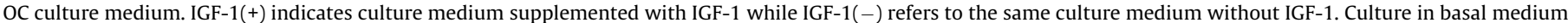

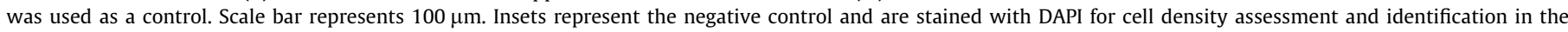
sections.

IGF-1 (+)

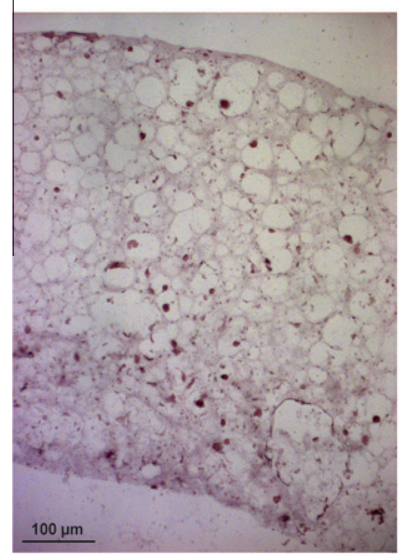

IGF-1 (-)

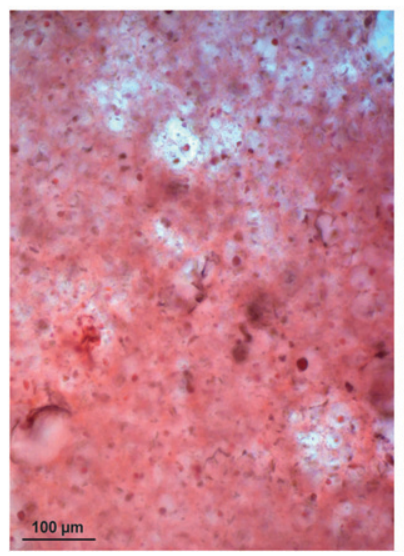

Basal

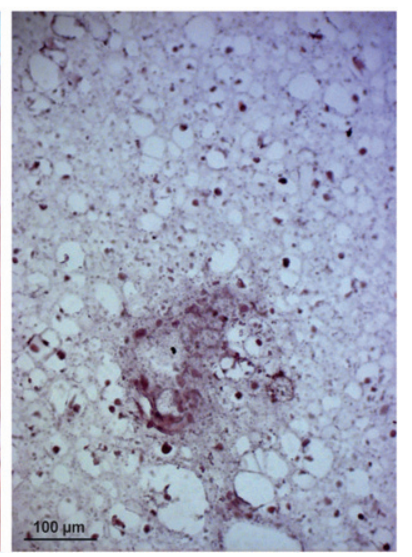

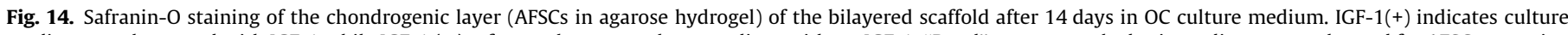

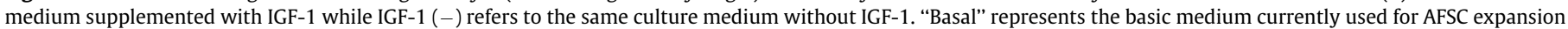
and maintenance, and was used as a control. Magnification, $200 \times$.

these cells. The results obtained herein are confirmed by the literature [34].

Alizarin red (AR) staining is a versatile procedure used to identify calcium-rich deposits and it can provide both qualitative and semi-quantitative data. Alizarin red stained AFSC-SPCL constructs cultured for 3 weeks in osteogenic supplemented medium, evidencing the presence of calcified ECM. Furthermore, the calcified matrix produced by AFSCs is detectable throughout the scaffold, indicating that cells are well distributed and the scaffold provides the necessary support to assist the synthesis of a mineralized ECM.

After AR solubilization, calcium contents were measured in order to quantify the amount of calcified ECM produced by the cells. The calcium content present in AFSC-SPCL is constant for up to 2 weeks in osteogenic medium $(p>0.05)$, showing similar values to our baseline control, day 0 , in which AFSCs from constructs were cultured in basal medium. From day 14 to day 21, the amount of calcium content significantly increases $(p<0.05)$, being almost $50 \%$ higher than levels from day 14 , suggesting that calcium is being added to the ECM, inducing the formation of a mineralized matrix in AFSC-SPCL constructs.
Since AFSCs were able to produce a calcified extracellular matrix after 21 days in osteogenic culture, these cells were considered osteoblastic-like cells, as osteoblasts are the bone cells associated with calcified matrix development.

Alizarin red and calcium content results support ALP activity data as calcification of an ECM is essential in achieving a complete in vitro bone-like ECM maturation.

\subsection{Agarose-SPCL bilayered system}

SEM morphological analysis was considered in this study so as to evaluate cell distribution throughout the osteogenic layer of the bilayered scaffolds and visualize the presence of mineralization aggregates, also called nodules. In Fig. 7, a dense layer of cells are covering SPCL scaffolds without completely closing the pores. Not only did cell distribution occur homogeneously but the presence of open pores allows the income of nutrients and oxygen into the inner sections of the construct. Moreover, the aggregates indicated by white arrows in Fig. 7 represent mineralization nodules typically associated to a calcified ECM. EDS analysis has been 
recently used to identify the elemental composition of a sample, including bone tissue [38], and was used to confirm and measure the calcium and phosphate composition on these structures.

Statistically, the percentage of atomic concentrations of calcium and phosphorus ions is preserved with the culturing time in both broad and mineral aggregates analysis. However, and as expected, the levels of these ions are significantly increased in the analysis over the mineral aggregates. When osteoblasts of native bone tissue become entrapped in bone ECM, these cells significantly reduce their metabolism as part of the natural process of bone mineral formation. As a consequence, cell proliferation rate decreases as cells are entrapped in the mineralized matrices they produced, which ultimately stabilizes the synthesis of ECM. In a similar way, the stability of calcium and phosphorus ions with time may be related to the response of AFSCs to the culture media and media stimuli to assist the production of mineralized matrix after 14 days in the bilayer co-cultures. During the process of bone hardening during aging, the $\mathrm{Ca} / \mathrm{P}$ ratio gradually increases from 1 to 1.67, the hydroxyapatite ratio reported for healthy bone [39]. Thus, in this study $\mathrm{Ca} / \mathrm{P}$ ratios were determined in the osteogenic layer of the bilayer system for each culturing condition and time point. The best results in terms of $\mathrm{Ca} / \mathrm{P}$ ratio were observed in basal medium conditions, which increase with time in culture, and whose $\mathrm{Ca} / \mathrm{P}$ ratio is the closest observed to that seen in natural bone. Although IGF-1 has been shown to be important for bone and cartilage tissue development, we did not find that the presence of this growth factor had any significant effect on the maintenance of the osteogenic phenotype of cells cultured in OC medium with IGF-1. According to the EDS data, AFSCs seem not to require supplementation provided by the osteochondral medium without IGF-1 to maintain the osteogenic phenotype in the developed bilayered system.

RunX-2 is an important transcription factor involved in osteogenic development and exogenous expression, which has been shown to enhance osteoblast-specific gene expression in rat bone marrow stromal cells as well as biological mineral deposition [40]. In the basal medium, RunX-2 expression was almost nonexistent, which indicates that in OC media with or without IGF, the osteogenic process is dynamic and evolving, and that mineralization development may still be taking place, since high levels of RunX2 expression have been shown to maintain the mineralization capacity of expanded marrow cells [40].

Conversely, safranin- $O$ staining suggests that the combination of other factors besides IGF-1 in the osteochondral medium maintains a higher level of chondrogenesis in the constructs, thus increasing the safranin-O staining in the constructs cultured in the OC medium.

Collagen type II and aggrecan expression were present in the chondrogenic layer of the bilayered constructs cultured in OC medium, indicating that in this media, AFSCs continue to produce ECM. Although aggrecan levels increase after 2 weeks in osteochondral media (with or without IGF-1), the collagen II levels remain stable, thus it is unlikely that AFSC-derived chondrocyte-like cells became hypertrophic in these constructs. Since the amount of collagen II is lower in basal medium, and the aggrecan expression barely present, the supplements in the osteochondral media seem to be important for long-term maintenance of a chondrogenic ECM.

\section{Conclusions}

This study demonstrated that AFSCs seeded onto SPCL scaffolds or encapsulated in agarose hydrogels remained viable even after these constructs were moved into the novel OC culture media. Furthermore, in the osteogenic layer (SPCL), osteogenically differentiated AFSCs did not require the OC media to maintain an osteogenic phenotype for up to 14 days, as they were able to continue produc- ing mineralized ECM even when cultured in basal culture medium. In agarose hydrogels, encapsulated AFSCs produced an ECM-rich in collagen type II and a mild presence of aggrecan protein. When cultured in OC media, the expression of collagen II is stable and aggrecan expression increases, although keeping low levels. Safranin-O staining clearly indicated that the cells continued to produce a cartilage-like ECM in OC medium without IGF supplement. In this bilayered system, IGF was not essential for the maintenance of chondrogenic or osteogenic phenotypes in differentiated AFSCs as evidenced by marker expression studies. However, the other supplements in the OC medium were revealed to be relevant for achieving long-term differentiation results.

This OC co-culture medium could be advantageous not only to simplify cell culture procedures but also to allow physical interaction between osteogenic and chondrogenic phenotypes while ensuring that the induced phenotype of chondrocytes and osteoblasts is maintained. In addition, this medium would reduce the time and production costs of a tissue engineered product and move it closer to a clinically applicable strategy for joint repair. Finally, the development of a bilayered $O C$ system for tissue engineering of bone/cartilage interfaces could better mimic the integration of bone and cartilage in an OC defect by providing scaffolds that address tissue specific needs. In this study, a bilayered scaffold of this type was successfully created in which both osteogenically and chondrogenically differentiated AFSCs maintained long term viability and phenotypic expression in vitro. Thus, the integrated agarose-SPCL scaffold proved to be functional it and may lead to the development of new strategies for $\mathrm{OC}$ repair and regeneration.

\section{Conflict of interest statement}

The authors have no conflict of interest to declare.

\section{Acknowledgements}

The authors wish to thank Dr. Jennifer Olson for editorial assistance with this manuscript. M.T. Rodrigues thanks the Portuguese Foundation for Science and Technology (FCT) for providing a PhD scholarship (SFRH/BD/30745/2006). This study was supported, in part, by Telemedicine and Advanced Technology Research Center (TATRC) at the US Army Medical Research and Materiel Command (W81XWH-07-1-0718).

\section{Appendix A. Figures with essential color discrimination}

Certain figures in this article, particularly Fig. 1-4, 6, and 10-14, are difficult to interpret in black and white. The full colour images can be found in the on-line version, at http://dx.doi.org/10.1016/ j.actbio.2012.04.013.

\section{References}

[1] Mauney JR, Volloch V, Kaplan DL. Role of adult mesenchymal stem cells in bone tissue engineering applications: current status and future prospects. Tissue Eng 2005;11:787-802.

[2] De Coppi P et al. Isolation of amniotic stem cell lines with potential for therapy. Nat Biotechnol 2007;25:100-6.

[3] Kolambkar YM, Peister A, Soker S, Atala A, Guldberg RE. Chondrogenic differentiation of amniotic fluid-derived stem cells. J Mol Histol 2007;38:405-13.

[4] Prusa AR, Marton E, Rosner M, Bernaschek G, Hengstschlager M. Oct-4expressing cells in human amniotic fluid: a new source for stem cell research? Hum Reprod 2003;18:1489-93.

[5] Fauza D. Amniotic fluid and placental stem cells. Best Pract Res Clin Obstet Gynaecol 2004;18:877-91.

[6] Diduch DR, Jordan LC, Mierisch CM, Balian G. Marrow stromal cells embedded in alginate for repair of osteochondral defects. Arthroscopy 2000;16:571-7. 
[7] Mauck RL, Yuan X, Tuan RS. Chondrogenic differentiation and functional maturation of bovine mesenchymal stem cells in long-term agarose culture. Osteoarthr Cartil 2006;14:179-89.

[8] Buschmann MD, Gluzband YA, Grodzinsky AJ, Kimura JH, Hunziker EB. Chondrocytes in agarose culture synthesize a mechanically functional extracellular matrix. J Orthop Res 1992;10:745-58.

[9] Gu WY, Yao H, Huang CY, Cheung HS. New insight into deformation-dependent hydraulic permeability of gels and cartilage, and dynamic behavior of agarose gels in confined compression. J Biomech 2003;36:593-8.

[10] Santos MI, Fuchs S, Gomes ME, Unger RE, Reis RL, Kirkpatrick CJ. Response of micro- and macrovascular endothelial cells to starch-based fiber meshes for bone tissue engineering. Biomaterials 2007;28:240-8.

[11] Gomes ME, Azevedo HS, Moreira AR, Ella V, Kellomaki M, Reis RL. Starchpoly(epsilon-caprolactone) and starch-poly(lactic acid) fibre-mesh scaffolds for bone tissue engineering applications: structure, mechanical properties and degradation behaviour. J Tissue Eng Regen Med 2008;2:243-52.

[12] Rodrigues MT, Gomes ME, Viegas CA, Azevedo JT, Dias IR, Guzón F, et al. Tissue engineered constructs based on SPCL scaffolds cultured with goat marrow cells: functionality in femoral defects. J Tissue Eng Regen Med 2011:5:41-9.

[13] Gomes ME, Holtorf HL, Reis RL, Mikos AG. Influence of the porosity of starchbased fiber mesh scaffolds on the proliferation and osteogenic differentiation of bone marrow stromal cells cultured in a flow perfusion bioreactor. Tissue Eng 2006;12:801-9.

[14] Tuzlakoglu K, Pashkuleva I, Rodrigues MT, Gomes ME, van Lenthe GH, Muller R, et al. A new route to produce starch-based fiber mesh scaffolds by wet spinning and subsequent surface modification as a way to improve cell attachment and proliferation. J Biomed Mater Res A 2010;92:369-77.

[15] Gonçalves A, Costa P, Rodrigues MT, Dias IR, Reis RL, Gomes ME. Effect of flow perfusion conditions in the chondrogenic differentiation of bone marrow stromal cells cultured onto starch based biodegradable scaffolds. Acta Biomater 2011;7:1644-52.

[16] Oliveira JT, Crawford A, Mundy JM, Moreira AR, Gomes ME, Hatton PV, et al. A cartilage tissue engineering approach combining starch-polycaprolactone fibre mesh scaffolds with bovine articular chondrocytes. J Mater Sci Mater Med 2007;18:295-302.

[17] Leonard CM, Fuld HM, Frenz DA, Downie SA, Massague J, Newman SA. Role of transforming growth factor-beta in chondrogenic pattern formation in the embryonic limb: stimulation of mesenchymal condensation and fibronectin gene expression by exogenenous TGF-beta and evidence for endogenous TGFbeta-like activity. Dev Biol 1991;145:99-109.

[18] Yoo JU, Barthel TS, Nishimura K, Solchaga L, Caplan AI, Goldberg VM, et al. The chondrogenic potential of human bone-marrow-derived mesenchymal progenitor cells. J Bone Joint Surg Am 1998;80:1745-57.

[19] Grimaud E, Heymann D, Redini F. Recent advances in TGF-beta effects on chondrocyte metabolism. Potential therapeutic roles of TGF-beta in cartilage disorders. Cytokine Growth Factor Rev 2002;13:241-57.

[20] Aubin JE. Osteoprogenitor cell frequency in rat bone marrow stromal populations: role for heterotypic cell-cell interactions in osteoblast differentiation. J Cell Biochem 1999;72:396-410.

[21] Maniatopoulos C, Sodek J, Melcher AH. Bone formation in vitro by stromal cells obtained from bone marrow of young adult rats. Cell Tissue Res 1988;254: 317-30.
[22] Franceschi RT, Iyer BS, Cui Y. Effects of ascorbic acid on collagen matrix formation and osteoblast differentiation in murine MC3T3-E1 cells. J Bone Miner Res 1994;9:843-54.

[23] Li J, Mareddy S, Tan DM, Crawford R, Long X, Miao X, et al. A minimal common osteochondrocytic differentiation medium for the osteogenic and chondrogenic differentiation of bone marrow stromal cells in the construction of osteochondral graft. Tissue Eng Part A 2009;15:2481-90.

[24] Butler AA, Yakar S, Gewolb IH, Karas M, Okubo Y, LeRoith D. Insulin-like growth factor-I receptor signal transduction: at the interface between physiology and cell biology. Comp Biochem Physiol B: Biochem Mol Biol 1998;121:19-26.

[25] Martel-Pelletier J, Boileau C, Pelletier JP, Roughley PJ. Cartilage in normal and osteoarthritis conditions. Best Pract Res Clin Rheumatol 2008;22:351-84.

[26] Vinatier $C$ et al. Cartilage tissue engineering: towards a biomaterial-assisted mesenchymal stem cell therapy. Curr Stem Cell Res Ther 2009;4:318-29.

[27] Meinel L et al. Localized insulin-like growth factor I delivery to enhance new bone formation. Bone 2003;33:660-72.

[28] Palmer LC, Newcomb CJ, Kaltz SR, Spoerke ED, Stupp SI. Biomimetic systems for hydroxyapatite mineralization inspired by bone and enamel. Chem Rev 2008; 108:4754-83.

[29] Rodrigues MT, Lee BK, Lee SJ, Gomes ME, Reis RL, Atala A, et al. The effect of differentiation stage of amniotic fluid stem cells on bone regeneration, submitted for publication.

[30] Tschan T, Hterler I, Houze Y, Winterhalter KH, Richter C, Bruckner P. Resting chondrocytes in culture survive without growth factors, but are sensitive to toxic oxygen metabolites. J Cell Biol 1990;111:257-60.

[31] Bougault C, Paumier A, Aubert-Foucher E, Mallein-Gerin F. Molecular analysis of chondrocytes cultured in agarose in response to dynamic compression. BMC Biotechnol 2008;8:71-81.

[32] Chang $\mathrm{CH}$ et al. Chondrogenesis from immortalized human mesenchymal stem cells: comparison between collagen gel and pellet culture methods. Artif Organs 2008;32:561-71.

[33] Beier F et al. Cell cycle genes in chondrocyte proliferation and differentiation. Matrix Biol 1999;18:109-20.

[34] Lian JB, Stein GS. Concepts of osteoblast growth and differentiation: basis for modulation of bone cell development and tissue formation. Crit Rev Oral Biol Med 1992;3:269-305.

[35] Aigner T, Stove J. Collagens - major component of the physiological cartilage matrix, major target of cartilage degeneration, major tool in cartilage repair Adv Drug Deliv Rev 2003;55:1569-93.

[36] Tuan RS. Biology of developmental and regenerative skeletogenesis. Clin Orthop Relat Res 2004;1:S105-17.

[37] Hipp J, Atala A. Sources of stem cells for regenerative medicine. Stem Cell Rev 2008;4:3-11.

[38] Mehta R, Chowdhury P, Ali N. Scanning electron microscope studies of bone samples: influence of simulated microgravity. Nucl Instrum Methods Phys Res B 2007;261:908-12.

[39] Dorozhkin SV. Calcium orthophosphates as bioceramics: state of the art. J Funct Biomater 2010;1:22-107.

[40] Byers BA, Garcia AJ. Exogenous RunX2 expression enhances in vitro osteoblastic differentiation and mineralization in primary bone marrow stromal cells. Tissue Eng 2004;10:1623-32. 